Bill Minerd of Syracuse wrapped up the session by exhibiting a new drive for a telescope, that he had manufactured at a very low price.

Following the papers session, many of the persons present adjourned to a nearby restaurant for a delicious meal. The day ended with a gathering at Ken Chilton's house, where the participants had a chance to exchange notes, make new friendships and rekindle old ones.

\title{
How to Find the Montreal Centre Observatory
}

Our little Observatory building is located on the upper McGill campus behind Molson Stadium. Many people have told us that they had difficulty in finding it. We admit that it is rather inconspicuous, especially when the surrounding trees are in leaf. We hope the chart, shown below (which may not be exactly to scale) and the following directions will be helpful.

1. Proceed up University past Pine Avenue.

2. Pass under archway that connects Royal Victoria Hospital and the Montreal Neurological Institute.

3. Take FIRST turn to the right. (It looks like a parking lot but is actually a road).

4. As you proceed along this road, Douglas Hall (a college residence) is on your left, and then the upper entrances to Molson Stadium on your right.

5. Just past Douglas Hall on your left is a flight of wooden stairs leading to a practice football field which is surrounded by a steel fence.

6. Leave your car in the parking area at the foot and mount the stairs.

7. At the top, pass through the gate, turn sharp right and follow the fence to the Observatory at the corner of the field. It is a grey stucco building with an aluminum dome.

The Observatory is open to visitors every Saturday evening year round. You will be very welcome.

Montreal Centre

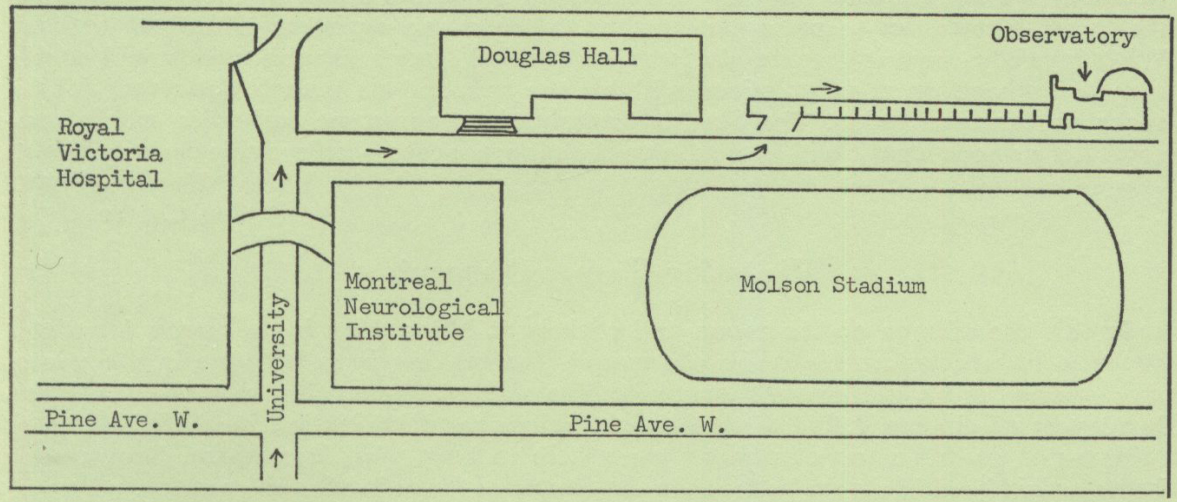

\section{Apollo 17: The Beginning, We Hope}

It is probably not often that an amateur gets to visit the largest spacecraft centre in the world. It must be indeed rare that he can tour Cape Kennedy and witness the launch of a mighty Saturn V rocket at the same time. However, such was the good fortune for five of us from Ottawa and Vancouver last December when we drove southward to cover the activities and launch of Apollo 17.

Cape Kennedy sprawls along an 84,000-acre section of the north-eastern Florida 
coast. Here the manned space programme began in 1961 and culminated in 1969 with the launching of the first space vehicle to land on the moon. The space centre has continued with the launching of six more moonships and is presently preparing for the Skylab and Spaceshuttle programme.

Each of our crew visiting the Cape had heard extensively about the facilities we were to see but we were nevertheless not prepared for the impact they were to have on our senses. It would be futile to relate the kind of feeling one gets when viewing launch complex 39-A from only 500 feet away, seeing the giant vehicle transport crawler, inspecting from the inside the voluminous Vehicle Assembly Building (VAB), and finally witnessing the spectacular night launch of the world's largest rocket. Suffice to say, these events rendered within us an awe that is nearly impossible to describe.

Apollo 17 was the last of the mighty moon ships. A note of sadness seemed to sing faintly at the KSC as work crews went through the Apollo countdown for the last time. Even the defiant Cocoa Beach motel signs displaying the words "Apollo 17 - the Beginning, not the End" seemed to possess an inward resignation. These people had made their living on the Apollo programme, too. Area motels had been booked since August 1972 for this event. The personnel I spoke to were clearly proud of their accomplishments and could not help but be awed by their own creations. No wonder. Amid the intensity of 7,500 foot candles that turned the sky to a blinding pink, I knelt and prayed that the burn would see those men into orbit. The remarkable sophistication of a computer network that guides a man to the moon was exceeded by the deafening, primitive blast that shoots him aloft. That no such blast will send a man to the moon again in this century has saddened the people who have made it possible. Oh, they have been compromised a little. The Skylab that will be launched next month will utilize more Saturn vehicles. The technicians in the VAB milled about and fussed over these vehicles while we were there. But one senses that the momentum generated by the moon programme has now been lost. Although the purposes and practicalities of the Skylab mission seem clear and indisputable, the people who build rockets at Cape Kennedy are not content. They are not content only to build and fly rockets that circle the earth. They want to reach out further to the moon again, to Mars and beyond. What is needed next is a space platform and orbital launch capability that will enable men to embark on these missions without the tremendous launch costs that inhibit space explorations today. The Skylab-Spaceshuttle programme embodies such a concept. Let us hope that it will lead man to the planets again - before this century is out!

KeN HewitT-White Ottawa Centre

\section{Hints for Happy Observing}

In this age of men on the moon and rockets to Mars there is no reason for a star gazer to be uncomfortable while observing! If observing is to be done in the winter the astronomer should be well insulated. The secret of warmth is not heavy clothes, but layers of clothes. I find a sweater and ski jacket combination ideal. Ski pants or "warm-up" pants on top of regular pants help to keep your legs warm. Snowmobile boots or insulated boots are better than gum boots as far as insulation goes.

The best light to read charts by is a flashlight that has the lens covered by red plastic tape (available in hardware stores). If lights are a problem, a blanket hung on a wire, suspended between two tall poles may be a help (a large rock is easier, but it is not recommended!).

When observing with a refractor it may be necessary to kneel down. A pillow in a plastic garbage bag really saves the knees. I hope some of these tips help you have more fun observing! 